\title{
Analysis of the IGF Axis in Preneoplastic Hepatic Foci and Hepatocellular Neoplasms Developing after Low-Number Pancreatic Islet Transplantation into the Livers of Streptozotocin Diabetic Rats
}

\author{
Jens-Gerd Scharf, Giuliano Ramadori, and Frank Dombrowski \\ Department of Medicine (J-GS, GR), Division of Gastroenterology and Endocrinology, Georg-August-Universität, \\ Göttingen, and Institute of Pathology (FD), Rheinische Friedrich-Wilhelms-Universität, Bonn, Germany
}

\begin{abstract}
SUMMARY: Preneoplastic hepatic foci have been demonstrated in liver acini, which drain the blood from intraportally transplanted pancreatic islets in streptozotocin-induced diabetic rats with mild persisting diabetes. In long-term studies of this animal model, hepatocellular adenomas and carcinomas (HCC) developed after a sequence of characteristic preneoplastic hepatic foci. In this experimental model, the local hyperinsulinism is thought to have a causative role. Because insulin and the insulin-like growth factor (IGF) axis are closely linked, an altered gene expression of the IGF axis components is likely. Therefore, preneoplastic hepatic foci and HCC were studied for the expression of IGF axis components. Glycogen-storing "early" preneoplastic hepatic foci were detectable several days after pancreatic islet transplantation. Northern blot analysis, in-situ hybridization, and immunohistochemical studies of these "early" lesions demonstrated increased expressions of IGF-I and IGF binding protein-4 (IGFBP-4) in altered parenchymal cells, and a decreased expression of IGFBP-1. IGF-II was not detected in these preneoplastic foci. HCC arising in this model had decreased expressions of IGF-I and IGFBP-4 but IGFBP-1 expression was not significantly altered. Some HCC showed a more than 100-fold overexpression of IGF-II, whereas other tumors were completely negative for IGF-II expression. Low IGF-I receptor expression was detected in preneoplastic foci and adjacent nonaltered liver tissue. However, HCC tissue consistently showed an increased IGF-I receptor expression, rendering these tissues susceptible to the mitogenic effects of IGF. The altered gene expression in glycogen-storing preneoplastic hepatic foci, especially the up-regulation of IGF-I and IGFBP-4 with the down-regulation of IGFBP-1, resemble the insulin-dependent regulation of these components in normal rat hepatocytes. These data agree with previous studies demonstrating a correspondence of the focal character, morphology, and enzyme pattern of preneoplastic hepatic foci with insulin effects on hepatocytes. The development from preneoplastic foci to HCC may be driven by insulin itself and/or an altered IGF axis component or yet unidentified factors. (Lab Invest 2000, 80:1399-1411).
\end{abstract}

\begin{abstract}
A n extensive array of growth factors and their respective receptors have been identified and may act as positive or negative modulators of cell proliferation and differentiation of malignant cell systems. Among these, the insulin-like growth factors I and II (IGF-I and IGF-II), their receptors and their binding proteins play an increasingly recognized role in tumor formation, growth, and metastasis in vivo (Macaulay, 1992; LeRoith et al, 1995a). During this process, a crucial role has been attributed to the IGF-I receptor (IGF-IR); IGF-IR has been shown to mediate mitogenic signals, to be protective from a variety of apoptotic injuries, and to be necessary for the transformation of certain types of cells (Baserga, 1999; LeRoith et al, 1995b). The IGF-II/mannose
\end{abstract}

Received April 27, 2000.

This work was supported by a grant from Deutsche Forschungsgemeinschaft, Grant number SFB 402 (A5, C6), GRK 335/2, Do 622/1-3, Scha 700/1-2.

Address reprint requests to: Dr. Jens-Gerd Scharf, Department of Medicine, Division of Gastroenterology and Endocrinology, Robert-Koch-Str. 40, D-37075 Göttingen, Germany. Fax: 49551 398279; E-mail: jscharf @med.uni-goettingen.de 6-phosphate receptor (IGF-II/M6PR), however, is thought to be a tumor suppressor gene (De Souza et al, 1997), because it is involved in transport of lysosomal enzymes; in binding, internalization, and degradation of IGF-II; and in activation of the mito-inhibitory transforming growth factor- $\beta$ (TGF- $\beta$ ) (Braulke, 1999).

Within circulation and tissue compartments, IGF is bound with high affinity to a family of structurally related binding proteins (IGFBP) (Bach and Rechler, 1995; Clemmons, 1997; Jones and Clemmons, 1995). Thus far, six distinct IGFBP have been characterized, which differ in molecular mass, IGF binding properties, and posttranslational modifications such as phosphorylation and glycosylation (Shimasaki and Ling, 1991). Many functions have been proposed for the IGFBP, including carrier proteins in the circulation, storage of IGF in specific tissue compartments, inhibition of IGF action by preventing access to IGF receptors, or potentiation of the mitogenic response by providing a stable source of available growth factor (Clemmons, 1997). In adult rats, the liver has been recognized as a main source of circulating IGF and of individual IGFBP (Bach and Rechler, 1995). Several 
studies have indicated that these proteins are produced in different hepatic cell populations. Rat hepatocytes have been shown to secrete IGFBP-1, IGFBP-2, and IGFBP-4 (Böni-Schnetzler et al, 1990; Menuelle et al, 1995; Villafuerte et al, 1991), whereas IGFBP-3 expression was only found in Kupffer cells, endothelial cells, and hepatic stellate cells (Scharf et al, 1995, 1996, 1998a; Villafuerte et al, 1994, 1995). IGF-I is mainly released from hepatocytes (Kachra et al, 1991; Scharf et al, 1998a; Scott et al, 1985a, 1985b).

IGF-II may play a role in hepatic carcinogenesis because increased IGF-II gene expression is found in liver tumors and precursor lesions (preneoplastic hepatic foci) in different animal models of hepatocarcinogenesis (Casola et al, 1995; Christofiori et al, 1994; Norstedt et al, 1988; Schirmacher et al, 1992; Yang et al, 1993; Yang and Rogler, 1991) and in human hepatocellular carcinomas (HCC) (Cariani et al, 1988). However, expression of the IGF receptors and IGFBP has received less attention in the context of hepatocarcinogenesis.

In different species and various animal models of hepatocarcinogenesis, a sequence of characteristic preneoplastic hepatic foci leading to hepatocellular adenomas (HCA) and HCC have been reported (Bannasch, 1996). Recently, preneoplastic hepatic foci have been demonstrated in liver acini, which drain the blood from intraportally transplanted pancreatic islets in streptozotocin-induced diabetic rats with mild persisting diabetes (Dombrowski et al, 1994, 1996). In long-term studies of this animal model, HCA and HCC developed after a sequence of characteristic preneoplastic lesions from glycogen-storing foci (GSF) over mixed-cell to basophilic-cell foci (Dombrowski et al, 1997). In this experimental model, the local hyperinsulinism is thought to have a causative role. Because insulin and the insulin-like growth factor (IGF) axis are closely linked, an altered gene expression of the IGF axis components is likely. Therefore, using this rat model of hepatocarcinogenesis, the expression of IGF axis components including IGF-I, IGF-II, IGF-IR, IGFII/M6PR, and individual IGFBP were examined in the sequence of preneoplastic hepatic foci and HCC.

\section{Results}

\section{mRNA Expression of IGF-I and IGFBP in Preneoplastic Hepatic Foci}

Figure 1 shows a representative northern blot analysis of total RNA isolated from GSF of two animals, 7 days after islet transplantation, and also from the left part of the liver of the same animals, which was free of islets and GSF. This analysis showed transcripts for IGF-I at $7.5 \mathrm{~kb}$, $4 \mathrm{~kb}, 2 \mathrm{~kb}$, and 1.0 to $1.5 \mathrm{~kb}$. Densitometric analysis revealed that levels of IGF-I mRNA were 2-fold to 3-fold higher in GSF compared with control liver (Fig. 1A). IGF-II-specific mRNA was not detectable in total RNA from GSF or control liver (data not shown). In both preneoplastic hepatic foci and control liver, IGFBP-1and IGFBP-4-coding mRNA transcripts were detected
A

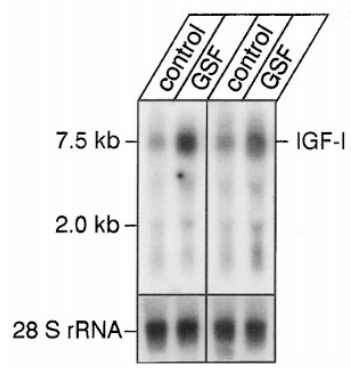

B

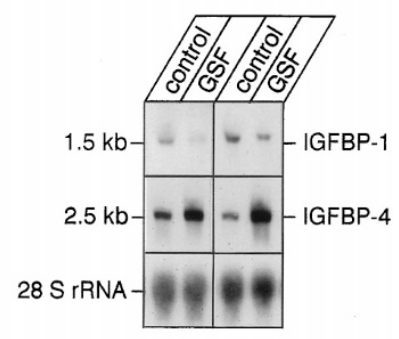

Figure 1.

Insulin-like growth factor-I (IGF-I) (A), IGF binding protein-1 (IGFBP-1), and IGFBP-4 $(B)$ mRNA expression of total RNA from the left (free of transplants) part of the livers (control) and from glycogen-storing foci (GSF) of the same liver 7 days after islet transplantation. Total RNA was size selected by $2 \%$ agarose gel electrophoresis. Membranes were hybridized using a labeled antisense RNA or a cDNA specific for rat IGF-I, IGFBP-1, or IGFBP-4, as indicated. The sizes of the hybridization bands are indicated on the right. To ensure equal loading of RNA, membranes were stripped and rehybridized with an oligonucleotide complementary to $28 \mathrm{~S}$ rRNA (lowest panel).

at $1.5 \mathrm{~kb}$ and $2.5 \mathrm{~kb}$, respectively. In total RNA isolated from GSF, IGFBP-1 transcripts were reduced to approximately $40 \%$ of control levels; levels of IGFBP-4 were increased 3-fold compared with control liver of the respective left lobe (Fig. 1B).

\section{In-Situ Hybridization (ISH) Experiments}

Seven days after islet transplantation, IGF-I and IGFBP expression patterns were examined in GSF by ISH using $\left[{ }^{35} \mathrm{~S}\right]-$ labeled antisense IGF-I, IGFBP-1, and IGFBP-4 riboprobes. Hybridization of the IGF-I antisense probe revealed an elevated expression of IGF-I in GSF compared with the surrounding liver tissue (Fig. 2A). The bright regions of the autoradiograms indicate areas of positive riboprobe hybridization under dark-field microscopy. Hybridization of an adjacent section of these preneoplastic hepatic foci with a sense IGF-I riboprobe was negative (data not shown), indicating that the hybridization signal observed with the antisense riboprobe was specific for IGF-I mRNA. In control liver, transcripts for IGFBP-1 and IGFBP-4 were homogeneously localized over parenchymal cells. ISH experiments for IGFBP-1 revealed a lower expression over parenchymal cells in GSF (Fig. 2B), whereas the amount of autoradiographic grains specific for IGFBP-4 was elevated in GSF compared with nonaltered acini (Fig. 2C).

\section{Immunohistochemical Analysis of IGF-I, IGF Receptors, and IGFBP in Preneoplastic Hepatic Foci and HCA}

The distribution of insulin, IGF polypeptides, their respective receptors, and IGFBP in GSF between 2 days and 24 months after islet transplantation and in normal rat liver was investigated by immunohistochemistry. Insulin was detected in $\beta$ cells of the transplanted islets located within the GSF (Fig. 3B). For IGF-I, a homogeneous expression over parenchymal cells of control liver was observed. In GSF, IGF-I immunoreactivity was in- 

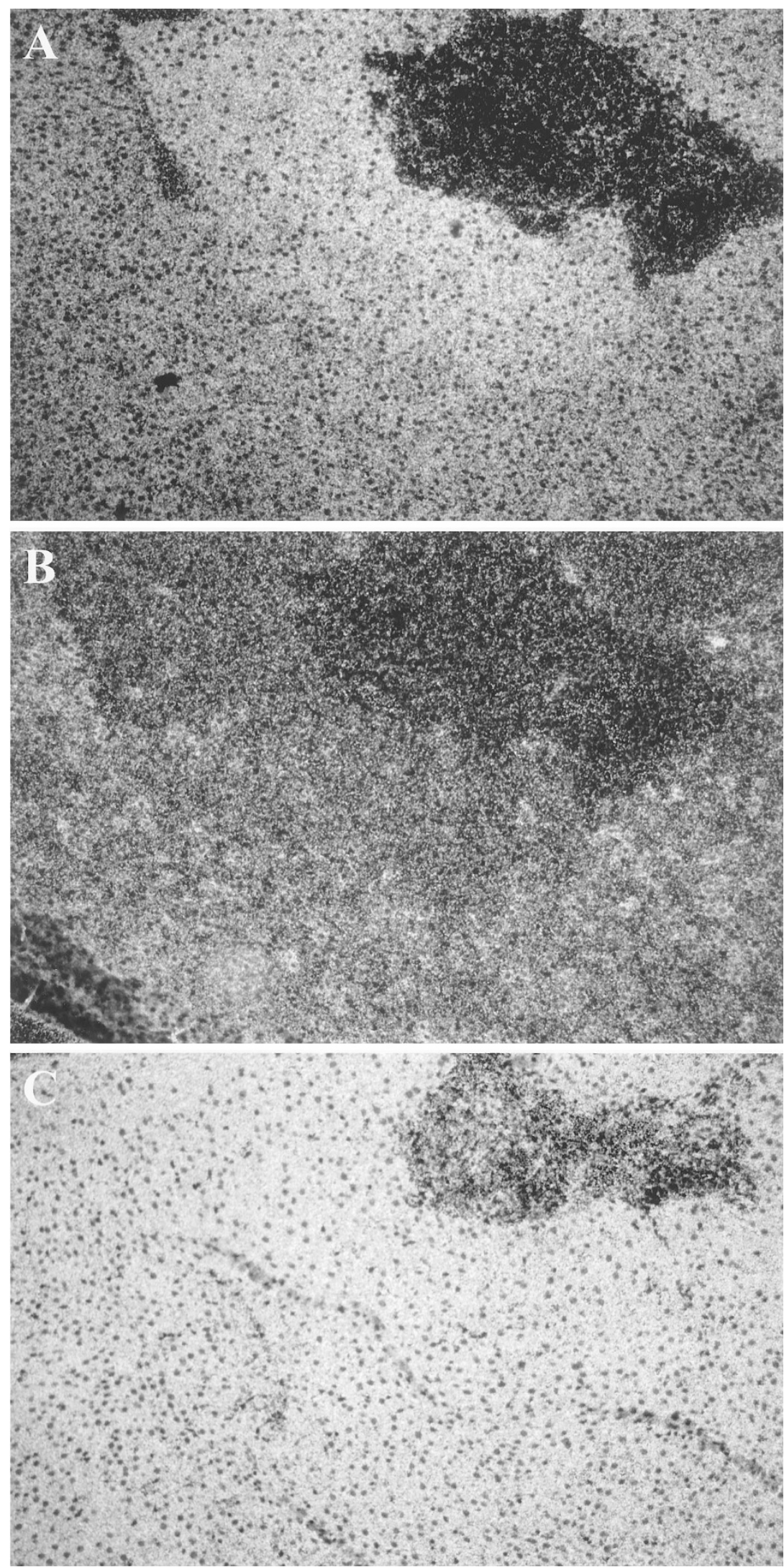

\section{Figure 2.}

In-situ hybridization (ISH) with $\left[{ }^{35}\right.$ S]-labeled IGF-I $(A)$, IGFBP-1 $(B)$, and IGFBP-4 $(C)$ antisense RNA probes of GSF surrounding a pancreatic islet (upper right part of the figure) 7 days after its transplantation into the liver. The islet shows no hybridization, whereas there is an increased number of autoradiographic grains specific for IGF-I and IGFBP-1 and a decrease of IGFBP-1 mRNA-specific signals over GSF, compared with the surrounding nonaltered liver tissue. Parallel sections are depicted in $A$ to $C$. Dark field illumination. Original magnification, $\times 120$. 

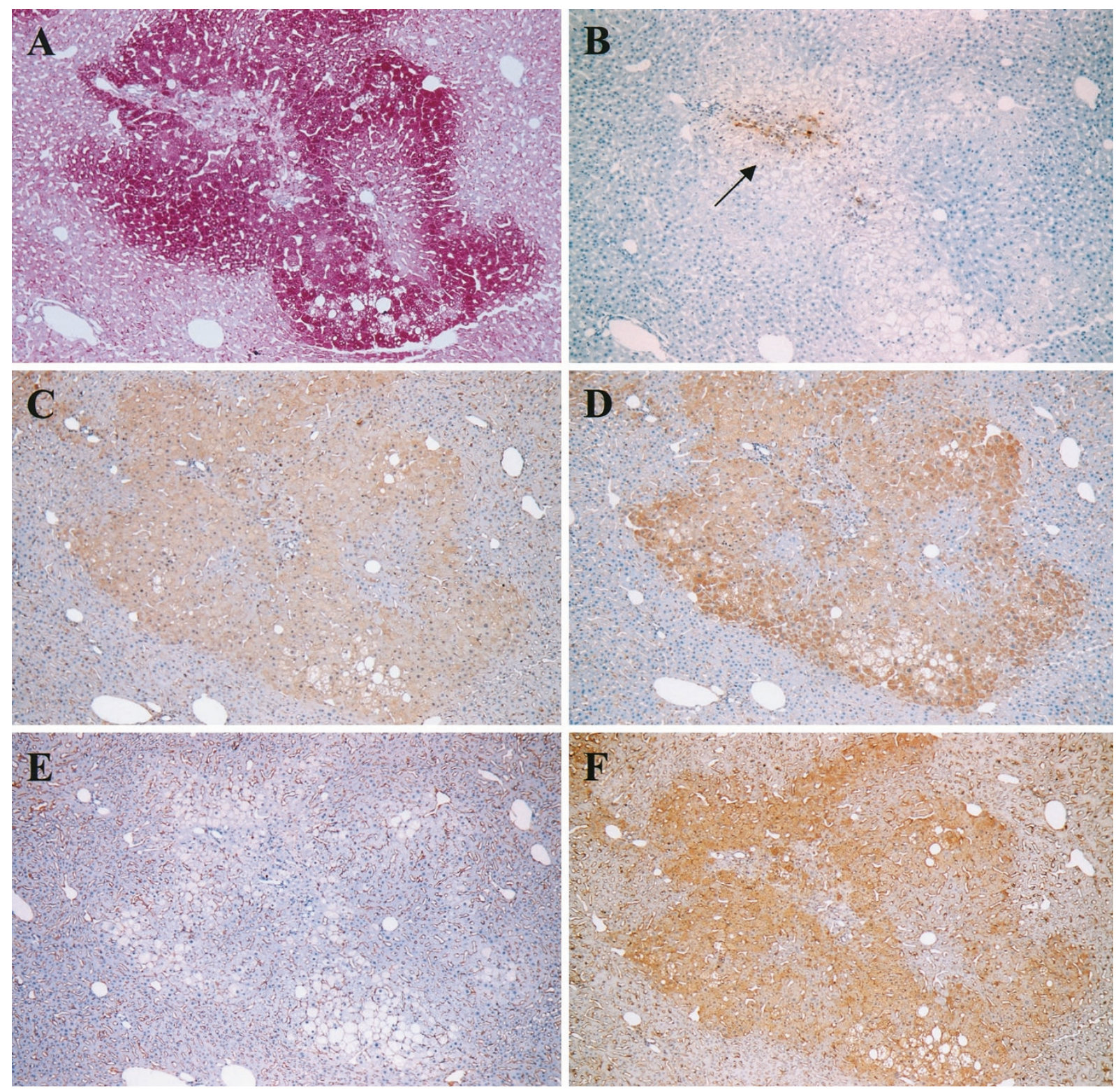

\section{Figure 3.}

Immunohistochemical localization of insulin $(B)$, IGF-I (C), IGFBP-4 (D), IGF-I receptor (IGF-IR) (E), and IGF-II/mannose 6-phosphate receptor (IGF-II/M6PR) ( $F)$ in a GSF 4 months after islet transplantation. Polyclonal antisera directed against insulin, IGF-I, IGFBP-4, the $\beta$ subunit of IGF-IR, and IGF-II/M6PR were used as primary antibodies. The periodic acid Schiff (PAS) reaction shows an increase of glycogen content in GSF $(A)$. In $B$, insulin-producing islet cells are indicated by an arrow. IGF-I, IGFBP-4, and IGF-II/M6PR expressions are increased in the GSF, and IGF-IR expression is unchanged compared with the surrounding liver tissue. Parallel sections are depicted in $A$ to $F$. Original magnification, $\times 70$.

creased compared with adjacent nonaltered acini (Fig. 3C). Similar to IGF-I, IGFBP-4 immunoreactivity was distributed over parenchymal cells of control liver in a homogeneous pattern. In comparison with surrounding nonaltered acini, GSF showed increased immunoreactivity for IGFBP-4 (Fig. 3D). In normal rat liver, IGF-IR was localized predominantly in hepatic stellate cells and along the sinusoids whereas hepatocytes showed only weak expression. In GSF, the IGF-IR expression pattern was not different from that observed in control liver or nonaltered acini (Fig. 3E). Immunohistochemistry of normal liver tissue revealed low levels of IGF-II/M6PR expression in hepatocytes with stronger expression along the sinusoids and in bile duct epithelial cells. IGF-II/
M6PR immunoreactivity was strongly enhanced in hepatocytes of GSF (Fig. 3F).

Immunohistochemical analysis of HCA that occurred between 6 and 24 months after islet transplantation revealed similar results to those found in GSF, an elevated expression of IGF-I, IGFBP-4, and IGF-II/ M6PR (Fig. 4). Compared with GSF, expression of IGF-IR in HCA was clearly increased (Fig. 4D).

\section{mRNA Expression of IGF-I and IGF-II, Their Respective Receptors, and IGFBP in HCC}

Quantitative analysis of northern blots after normalization with a $28 \mathrm{~S}$ ribosomal RNA probe demonstrated 

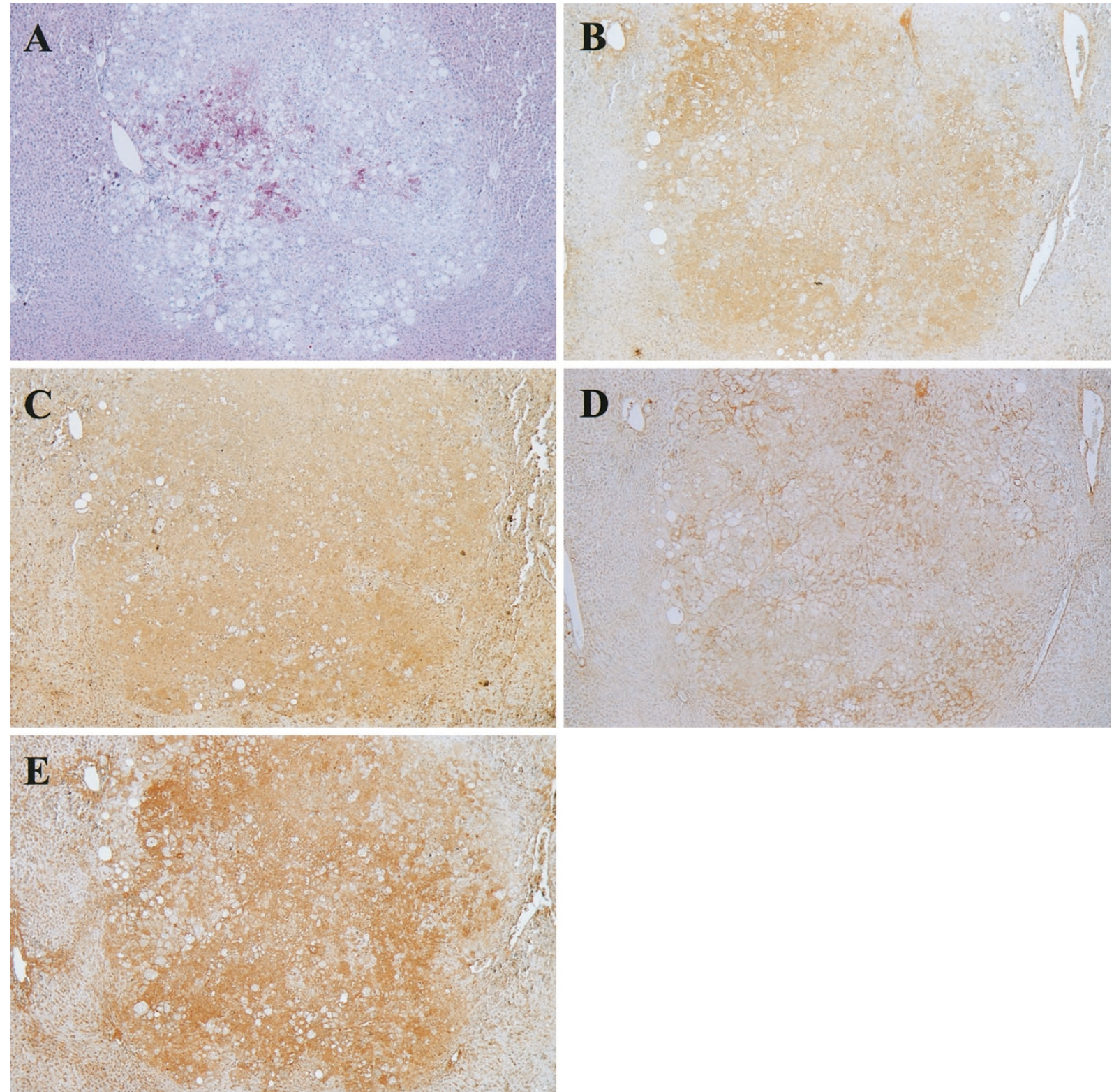

\section{Figure 4.}

Immunohistochemical localization of IGF-I $(B)$, IGFBP-4 $(C)$, IGF-IR $(D)$, and IGF-II/M6PR $(E)$ in a small hepatocellular adenoma (HCA) 18 months after islet transplantation. The PAS reaction shows that only a part of the adenoma contains glycogen-storing hepatocytes and that some tumor cells are PAS-negative $(A)$. Similar to GSF, shown in Figure 3, expressions of IGF-I, IGFBP-4, and IGF-II/M6PR are increased. IGF-IR is also increased in the HCA compared with the nontumorous liver tissue and the GSF. Parallel sections are depicted in $A$ to $E$. Original magnification, $\times 25$.

that the $7.5 \mathrm{~kb}, 4 \mathrm{~kb}, 2 \mathrm{~kb}$, and 1.0 to $1.5 \mathrm{~kb}$ IGF-I mRNA steady state levels were decreased in HCC tissue to approximately $70 \%$ of the levels observed in normal liver. The expression of IGF-II was strikingly heterogeneous in HCC. Some tumors were completely negative whereas other tumors showed a more than 100-fold increase in IGF-II expression (Fig. 5A). Steady state levels of IGF-IR and IGF-II/M6PR were detectable at $11 \mathrm{~kb}$ and $9.0 \mathrm{~kb}$, respectively. IGF-IR expression was consistently increased approximately 2-fold in HCC in comparison with nontumorous liver tissue, whereas IGF-II/M6PR expression was elevated approximately 1.5-fold, as determined by densitometric analysis (Fig. 5B). IGFBP-1 mRNA was detectable with no appreciable differences between tumoral and nontumorous liver tissue in some $\mathrm{HCC}$, or was moderately increased in some HCC that had marked IGF-II overexpression. Furthermore, northern blot analysis showed that IGFBP-4 mRNA was significantly downregulated in all $\mathrm{HCC}$, to approximately $55 \%$ of control levels (Fig. 5C).

\section{ISH Experiments in HCC}

In HCC tissue, ISH experiments revealed a heterogeneous distribution of mRNA-specific grains; adjacent nontumorous liver tissue showed more homogeneous expression patterns. Figure 6 shows an example of an 
A

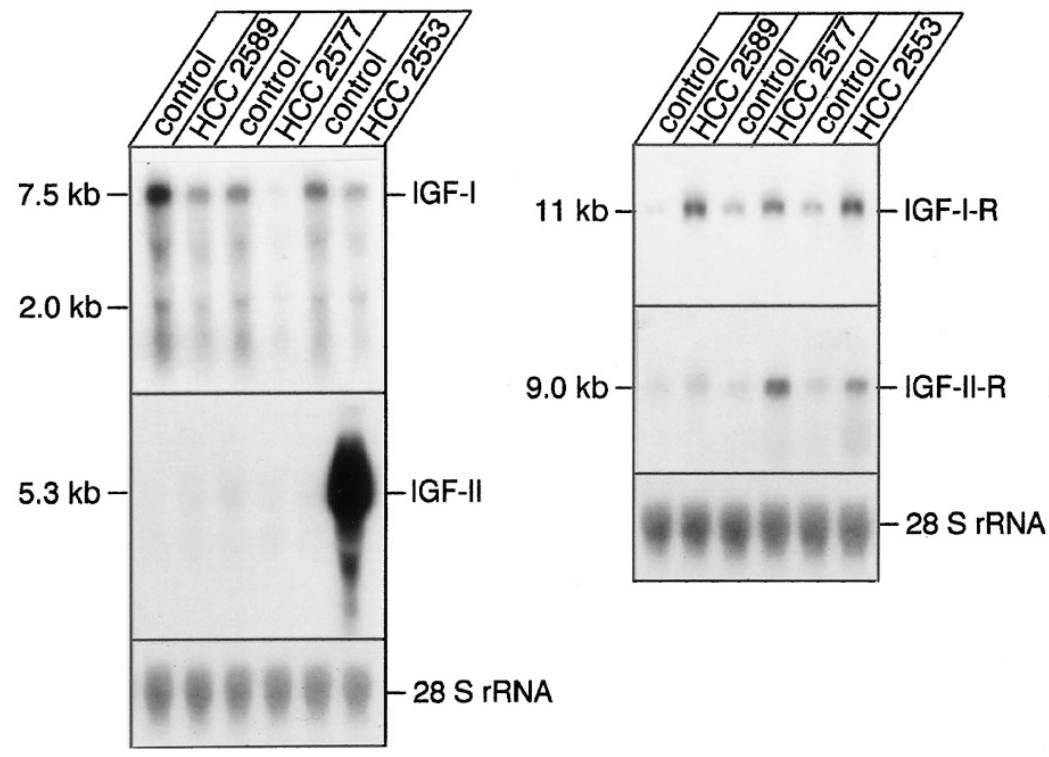

C

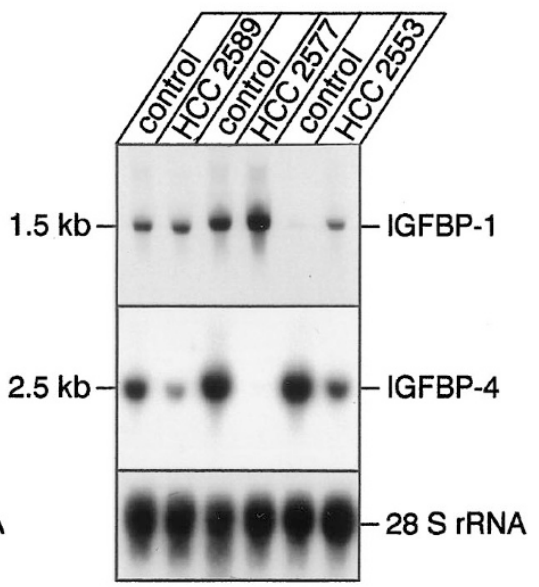

Figure 5.

IGF-I and IGF-II $(A)$, IGF-IR and IGF-II/M6PR $(B)$, and IGFBP-1 and IGFBP-4 (C) mRNA expression in hepatocellular carcinomas (HCC) that developed in the right part of the livers after low-number pancreatic islet transplantation. The left parts of the same livers, which were free of transplants and of tumors, were used as controls. Total RNA isolated from controls and HCC was separated by a $2 \%$ agarose gel electrophoresis. Membranes were hybridized using labeled probes specific for IGF-I and IGF-II $(A)$, for IGF-IR and IGF-II/M6PR $(B)$, and for IGFBP-1 and IGFBP-4 $(C)$, as indicated. The sizes of the hybridization bands are indicated on the right. To ensure equal loading of RNA, membranes were stripped and rehybridized with an oligonucleotide complementary to $28 \mathrm{~S}$ rRNA (Iowest panel).

IGF-II-overexpressing HCC with a high level of IGF-II expression throughout the tumor (Fig. 6B). IGF-II mRNA-specific grains were barely detectable in the adjacent nontumorous liver. Levels of IGF-I and IGFBP-4 mRNA were significantly reduced over tumor tissue compared with normal liver tissue (Fig. 6, A and D), confirming the northern blot analysis. IGFBP-1 mRNA was present at approximately the same level in HCC and nonaltered adjacent liver tissue (Fig. 6C).

\section{Immunohistochemical Analysis of HCC}

Immunohistochemical analysis for IGF-I and IGFBP-4 demonstrated lower immunoreactivity over HCC tissue than over adjacent nontumorous liver, confirming results from northern blotting and ISH (Fig. 7, B and C). Immunolabeling for IGF-IR showed a barely detectable low immunoreactivity over normal liver tissue as stated above. However, strong immunoreactivity for IGF-IR was observed in HCC, with a homogeneous distribution over the tumor tissue (Fig. 7D). For IGF-II/ M6PR, a moderately increased immunoreactivity was noted over the tumor tissue compared with surrounding normal liver (Fig. 7E).

\section{Discussion}

To investigate the possible role of components of the IGF axis during liver carcinogenesis, we have taken advantage of the stepwise progression toward HCC developing after low-number pancreatic islet transplantation into the livers of streptozotocin-induced diabetic rats. In this model, a sequence of clear glycogen-storing and fat-storing foci over mixed-cell foci and basophilic-cell foci leading to HCA and HCC have been observed (Dombrowski et al, 1997). Because these lesions were located in close anatomical relationship to the transplanted islets of Langerhans, products of islet secretion are thought to be causative factors resulting in the glycogen-storing and fatstoring liver acini (Dombrowski et al, 1994). The local hyperinsulinemia (together with other peptides) might cause the demonstrated findings. The phenotype of early preneoplastic liver lesions induced by various agents (such as chemicals, viruses, and radiation), namely, GSF and, in some aspects, mixed-cell foci, resemble the metabolic effects of insulin on hepatocytes (Bannasch, 1996; Klimek and Bannasch, 1993). Vice versa, the model of islet transplantation used in the present study produced alterations of liver acini induced by insulin which resemble preneoplastic liver lesions in their focal character, morphology, and enzyme pattern (Dombrowski et al, 1994, 1996). Longterm studies have shown that these altered acini represent preneoplastic foci and proceed to neoplasms (Dombrowski et al, 1997).

Because of the structural homologies among insulin, IGF-I, and IGF-II and among their respective receptors, changes of the hepatic expression of the IGF axis might occur after islet transplantation into the livers of diabetic rats and these changes might contribute to the pathogenesis of tumor development observed in this model. The present study revealed marked alterations of the IGF axis detectable a few days after islet transplantation in GSF, namely ele- 

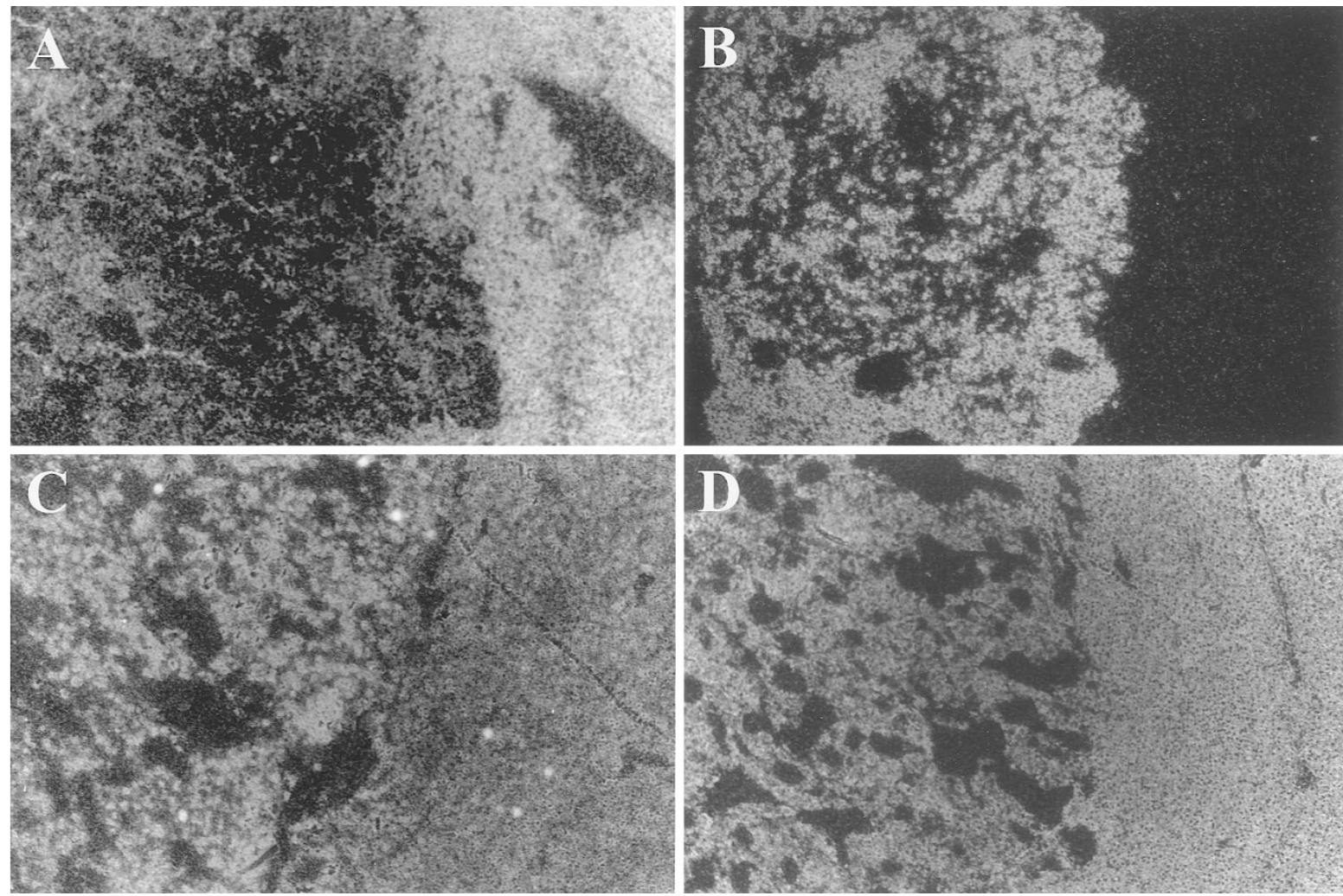

\section{Figure 6.}

ISH with $\left[{ }^{35}\right.$ S]-labeled antisense RNA probes in parallel sections of a HCC (left part of the figures), 24 months after islet transplantation. A strong increase of IGF-I $(B)$ and decreases of IGF-I $(A)$ and IGFBP-1 $(D)$ mRNA expression compared with the neighboring nontumorous liver tissue (right part of the images) is seen. IGFBP-1 (C) mRNA was present at approximately the same levels in tumorous and nontumorous liver tissue. Dark field illumination. Original magnification, $\times 40$.

vated expressions of IGF-I and IGFBP-4 associated with a decreased expression of IGFBP-1. At this stage of hepatocarcinogenesis, IGF-II was barely detectable in preneoplastic foci or nonaltered acini. IGF-II expression in HCC was heterogeneous, some tumors showed strong IGF-II overexpression and some tumors showed no IGF-II expression. IGF-IR was expressed at low levels in preneoplastic foci, whereas strong IGF-IR expression was detected in HCC, rendering tumor cells susceptible to the mitogenic effects of autocrine and paracrine IGF. Rat hepatocytes in primary culture have been used for investigations regarding the mechanisms of regulation of IGF-I and IGFBP production. These studies demonstrated that regulation of these hepatocyte-derived factors is under the control of a number of hormones, including insulin (Bach and Rechler, 1995). In primary cultures of hepatocytes, insulin is a strong inhibitor of IGFBP-1 expression (Pao et al, 1993; Scharf et al, 1996; Villafuerte et al, 1992); IGF-I expression (Böni-Schnetzler et al, 1991; Pao et al, 1993; Phillips et al, 1991) and IGFBP-4 expression (Scharf et al, 1996) are stimulated by insulin treatment. The altered gene expression of IGF axis components in preneoplastic hepatic foci early after islet transplantation, down-regulation of IGFBP-1 expression and up-regulation of IGF-I and IGFBP-4, resembled the regulatory effects of insulin in primary cultures of liver cells.
So far, a comprehensive study on IGF and IGFBP expression in various stages of hepatocarcinogenesis has only been performed in woodchuck hepatitis virus carrier woodchuck liver. These studies demonstrated an overexpression of IGF-II in more than $90 \%$ of preneoplastic hepatic foci in precancerous woodchuck liver and in HCC derived from this model (Yang et al, 1993; Yang and Rogler, 1991). Furthermore, ISH studies demonstrated that IGFBP-1 and IGFBP-2 were down-regulated in preneoplastic hepatic foci and in HCC tumor tissue compared with the adjacent normal liver, whereas IGFBP-4 was up-regulated (Rogler et al, 1995). Although in the HCC model presented in this study IGF-II overexpression was detectable in $\mathrm{HCC}$ but not in preneoplastic foci, the altered IGFBP expression in preneoplastic foci is comparable to that reported by Rogler et al (1995). This is remarkable for two reasons: i) HCC developing in these animal models were induced by two different agents (viral versus hormonally induced HCC) and ii) as stated above, alterations of IGF axis expression in both models resembled the metabolic effect of insulin on hepatic expression of these factors.

Despite the similarities of IGFBP expression observed in these two models, the biologic actions of IGFBP, whether they enhance or attenuate the effects of IGF, can hardly be predicted in an in vivo animal model. In the case of IGFBP-1, both inhibition and 

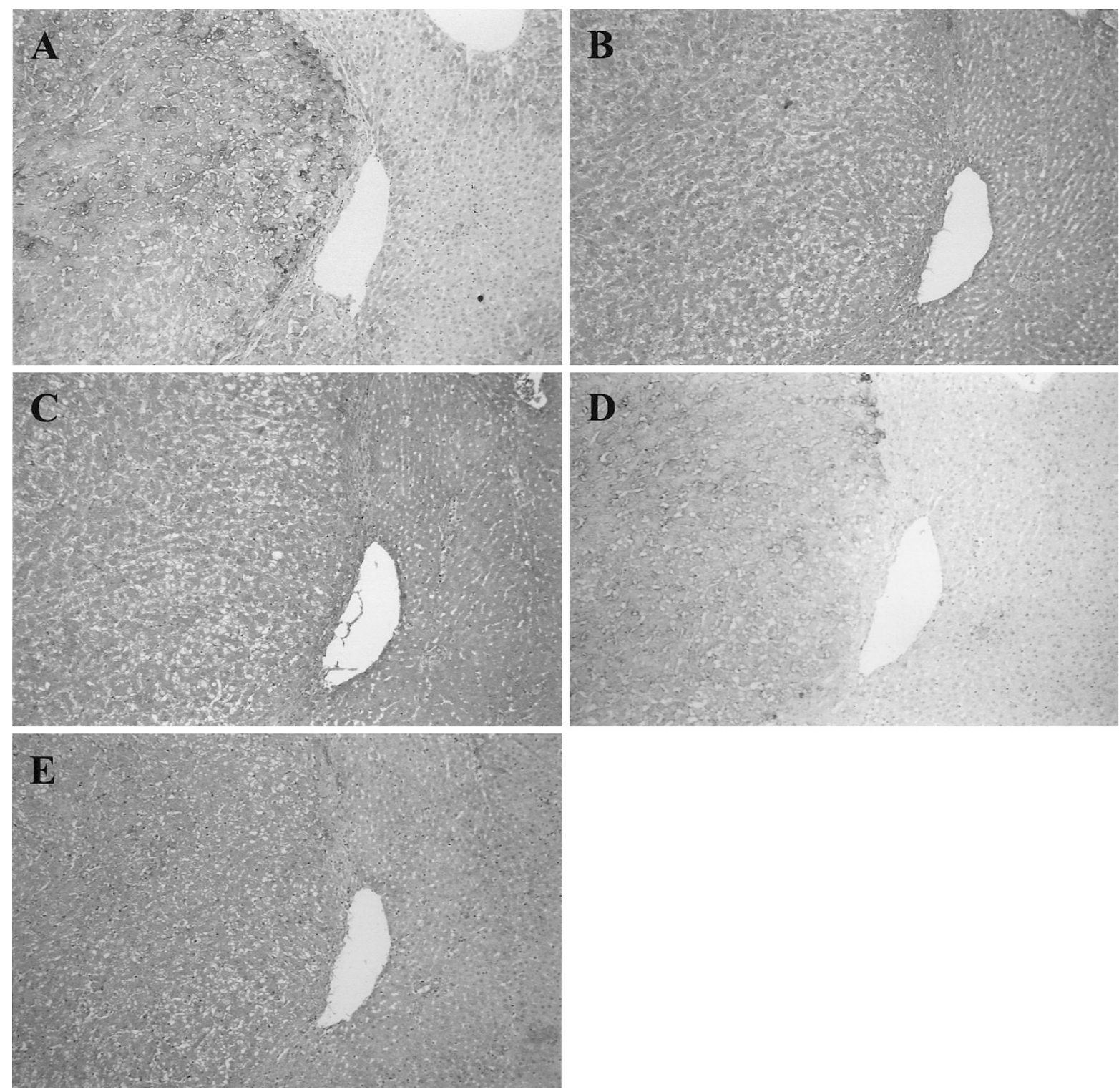

\section{Figure 7.}

Immunohistochemical localization of IGF-I $(B)$, IGFBP-4 $(C)$, IGF-IR $(D)$, and IGF-II/M6PR $(E)$ in parallel sections of a highly differentiated HCC (left part of the figures), 19 months after islet transplantation and in nontumorous liver tissue (right part of the figures). The HCC shows a strongly increased IGF-IR expression (D) when compared with the neighboring liver tissue. PAS reaction $(A)$. Original magnification, $\times 70$.

stimulation of IGF actions have been reported (Clemmons, 1997). Although tissue IGF-I and IGFBP were not measured quantitatively in the present study, an elevated expression of IGF-I together with a decreased expression of IGFBP-1, as observed in preneoplastic foci, is likely to result in an excess of IGF-I over IGFBP-1. Interestingly, under similar experimental conditions, when IGFBP-1 was added to porcine aortic smooth muscle cell or human fibroblast cultures with a molar excess of IGF-I to IGFBP-1, there was a further enhancement of the effects of IGF-I on DNA synthesis (Busby et al, 1988; Elgin et al, 1987). IGFBP-4 is the only IGFBP that consistently inhibits IGF-I action in vitro (Clemmons, 1997). However, IGFBP-4 knock-out mice showed growth deficits compared with the wild type strain, indicating that the in vivo role of IGFBP-4 is more likely to optimize IGF action than to inhibit it (Pintar et al, 1998). Taken together, these data suggest that the altered IGFBP-1 and IGFBP-4 expression observed in preneoplastic foci might result in a condition that potentiates the mitogenic effects of IGF. However, for a definitive statement on the role of IGFBP during the process of hepatocarcinogenesis, the model of islet transplantation needs to be transferred to mice carrying a targeted disruption for one of these IGFBP or to IGFBP transgenic mice.

In the liver, IGF/insulin-mediated signal transduction may occur through binding to either the insulin receptor (IR) and/or the IGF-IR. Very few high-affinity binding sites for IGF-I have been demonstrated on adult rat hepatocytes (Caro et al, 1988), consistent with the low IGF-IR expression in preneoplastic hepatic foci and in normal hepatocytes of adjacent liver tissue seen in the 
present study. Furthermore, short-term and long-term metabolic actions of IGF-I on primary cultures of rat hepatocytes have been attributed to low-affinity IGF-I binding to the IR (Hartmann et al, 1990). Thus, the enhanced cell proliferation observed in preneoplastic hepatic foci (Dombrowski et al, 1994) is likely to be mediated via the IR rather than the IGF-IR. Increased IR expression associated with an activated signal transduction cascade, such as IRS-1, raf-1, and MEK-1, has been demonstrated in the preneoplastic hepatic foci observed in this animal model (F Dombrowski and J Sun, unpublished data). However, despite high proliferative activity, the growth rate of these preneoplastic hepatic foci was limited by the high apoptotic activity also observed in these foci (Dombrowski et al, 1994). During the development from preneoplastic hepatic foci to HCA and HCC, mitotic activity increased to a higher magnitude than the rate of apoptosis (Dombrowski et al, 1997). This shift towards a net increase of proliferation might be related to i) a decrease of $I R$ and IRS-1, raf-1, and MEK-1 expression and ii) an increase of IGF-IR expression during the progression to $\mathrm{HCC}$, as observed in the present study. Recent studies show that apoptosis can be blocked by activated IGF-IR in different cell types (Baserga et al, 1997; Baserga, 1999). Apart from its anti-apoptotic function, the $\beta$ subunit of IGF-IR is ten times more mitogenic than the $\beta$ subunit of the IR (Lammers et al, 1989). Thus, the development of hepatocellular adenomas and carcinomas in this animal model might be related to both the mitogenic and anti-apoptotic effects of IGF-IR. In this context, it is notable that IGF-IR can be stimulated by high concentrations of insulin in addition to IGF. Prisco et al (1999) demonstrated that insulin concentrations of 50 $\mathrm{ng} / \mathrm{ml}$ were sufficient for IGF-IR activation. In the presented model of hepatocarcinogenesis, this might be relevant for IGF-IR expressing cells in small hepatocellular adenomas that are exposed to both IGF-I and insulin secreted by the transplanted islets. Although not studied in the present study, the involvement of IR/IGF-IR hybrids during hepatocarcinogenesis should be discussed. A recent study by Bailyes et al (1997) demonstrated that hybrid insulin/IGF receptors are widely distributed in mammalian tissues, including the liver. However, their signaling properties and functions under physiologic and pathophysiologic conditions has to be determined.

Furthermore, TGF- $\alpha$ expression also increases during the development from glycogen-storing liver acini to hepatocellular carcinoma in the animal model used in the present study (Dombrowski et al, 1997). TGF- $\alpha$ is known to interact with the EGF receptor (Wells, 1999) and the EGF receptor requires the presence of a functional IGF-IR for its mitogenic and transforming activities (Coppola et al, 1994). These data suggest that multiple growth factors, including insulin, IGF, and TGF- $\alpha$, are involved in the stepwise development of hepatocarcinomas in the animal model of islet transplantation used in the present study.

IGF-II/M6PR is thought to be a tumor suppressor gene because of its essential functions in the degra- dation of the mitogen IGF-II, the activation of the growth inhibitor TGF- $\beta$, and the transport of lysosomal proteases (Braulke, 1999). In a variety of tumor cell lines and in rat and human HCC, the expression of IGF-II/M6PR has been reported to be significantly reduced (Jirtle et al, 1994; Sue et al, 1995). Furthermore, a loss of heterogeneity (LOH) at the IGF-II/ M6PR locus with point mutations in the remaining allele has been detected in approximately $70 \%$ of patients with HCC in the United States (De Souza et al, 1995). Several of these mutations disrupt the ligand binding functions of intact IGF-II/M6PR (Byrd et al, 1999), further supporting the hypothesis that IGF-II/ M6PR is a tumor suppressor gene. These data are in contrast to a recently published study on HCC in Japan that failed to detect genetic alterations of IGFII/M6PR (Wada et al, 1999), which renders the role of IGF-II/M6PR in hepatocarcinogenesis controversial. Using the same animal model presented in the current study, an up-regulation of IGF-II/M6PR expression was observed in preneoplastic hepatic foci early after islet transplantation, in HCA and HCC. Although these observations are in line with an elevated IGF-II/M6PR expression in rat livers treated with peroxisome proliferators (Rumsby et al, 1994), they suggest a role of IGF-II/M6PR in limiting the mitogenic effects of IGF-II in these HCC models.

In conclusion, we demonstrated marked alterations in the hepatic expression of components of the IGF axis in preneoplastic hepatic foci after low-number islet transplantation into the livers of diabetic animals. These alterations perfectly mimicked the metabolic effects of insulin on primary cultures of hepatocytes. The elevated expression of IGF-I with down-regulation of IGFBP-1 and up-regulation of IGFBP-4 observed in preneoplastic hepatic foci might provide a milieu that potentiates the mitogenic effects of IGF-I. At this early stage of hepatocarcinogenesis, IGF-I is thought to exert its effects through interaction with the IR, because IGF-IR is barely detectable in preneoplastic hepatic foci. However, an elevated IGF-IR expression is consistently detectable in HCC tissue, rendering the tumor tissue susceptible to either IGF-II, which is overexpressed in some of the HCC, or to IGF-I from the adjacent nontumorous liver tissue.

\section{Materials and Methods}

\section{Materials}

$\left[{ }^{35} \mathrm{~S}\right]-U T P \alpha \mathrm{S}$ (specific activity, $>1000 \mathrm{Ci} / \mathrm{mmol}$ ) was purchased from Amersham-Buchler (Braunschweig, Germany), and [ $\left.{ }^{32} \mathrm{P}\right]-\mathrm{dCTP}$ (specific activity, $3000 \mathrm{Ci} /$ mmol) from Hartmann Analytic (Braunschweig, Germany). The ${ }^{\mathrm{T} 7}$ Quick prime kit was obtained from Pharmacia (Uppsala, Sweden) and the nick translation kit from GIBCO BRL Life Technologies (Gaithersburg, Maryland).

\section{Antibodies}

Antibodies to rat IGFBP were supplied by Dr. Ling and Dr. Shimasaki (The Whittier Institute for Diabetes and 
Endocrinology, La Jolla, California). A rabbit polyclonal antiserum to rat IGF-I was supplied by DSL (Webster, Texas), a polyclonal antiserum to insulin by DAKO (Hamburg, Germany) and an antiserum directed against the $\beta$-subunit of the human IGF-IR by Santa Cruz (Heidelberg, Germany). IGF-II/M6PR from rat liver was purified (von Figura et al, 1984) and an antiserum was raised in rabbits (Schmitz et al, 1995). Biotinylated mouse monoclonal antibodies against rabbit and goat IgG were obtained from Dianova (Hamburg, Germany) and horseradish peroxidaseconjugated streptavidin from Zymed Laboratories (San Francisco, California).

\section{cDNA Probes}

The following cDNA probes were used for northern blot analysis and ISH experiments: a 407 bp fragment of rat IGFBP-1 cDNA, clone pRBP-1-501 (Shimasaki and Ling, 1991), a 444 bp fragment of rat IGFBP-4 cDNA, clone pRBP4-SH (Shimasaki and Ling, 1991), a 700 bp fragment of rat IGF-I cDNA provided by Dr. Schwander and Dr. Margot (Department of Internal Medicine, Basel, Switzerland), a $500 \mathrm{bp}$ fragment of rat IGF-II cDNA (Stylianopoulou et al, 1988), a 265 bp fragment of rat IGF-IR cDNA (Werner et al, 1989), a $500 \mathrm{bp}$ fragment of the rat IGF-II/M6PR cDNA provided by Dr. LeRoith and Dr. Roberts (National Institutes of Health, Bethesda, Maryland). An oligonucleotide (5' AAC GAT CAG AGT AGT GGT ATT TCA CC 3') complementary to $28 \mathrm{~S}$ rRNA was used to quantify northern blots.

\section{Animals and Experimental Groups}

Diabetes was induced in adult male Lewis rats (inbred strain) weighing 250 to $300 \mathrm{~g}$ by treatment with streptozotocin (80 mg per kg body weight). Diabetes was defined by a nonfasting blood glucose level higher than $400 \mathrm{mg} / \mathrm{dl}$ manifested 1 to 3 days after streptozotocin administration. The transplantation procedure was performed as previously described (Dombrowski et al, 1994, 1996, 1997, 1998). Briefly, in the main group, a small number of islets of Langerhans ( $n=250$ to 450 ) freshly isolated from isologous healthy male rats was transplanted via the portal vein into the right part of the livers of 46 animals. Before infusion of the islets in the portal vein, the branch of the portal vein supplying the left lobe and the left part of the middle lobe was occluded by a vessel clamp. After transplantation, the clamp was removed after a maximal time of ischemia of 1 minute. The number of islets was chosen to be so low that mild hyperglycemia persisted for at least 10 months after islet transplantation (Dombrowski et al, 1997, 1998). From 2 days up to 24 months after transplantation, the animals were killed under anesthesia and tissue was processed as described in "Processing of Liver Tissue". Housing and treatment of animals conformed to the guidelines of the Society for Laboratory Animals Service (GV-Solas) and the German animal protection law.

\section{Processing of Liver Tissue}

Tissue was processed as previously described (Dombrowski et al, 1997). Briefly, under anesthesia, the aorta was cannulated and the animal was perfused with Ringer's solution containing $0.5 \%(\mathrm{v} / \mathrm{v})$ procaine and $4 \%(\mathrm{w} / \mathrm{v})$ dextran for 2 minutes followed by fixation using a cocktail of Ringer's solution, $4 \%(w / v)$ dextran, $0.3 \%(\mathrm{v} / \mathrm{v})$ glutaraldehyde, and 3\% (v/v) formaldehyde freshly prepared from paraformaldehyde, before removing the liver. Approximately 2- to 3-mm thick sections were dehydrated and embedded in paraffin. From the paraffin-embedded liver specimens, serial sections were cut and stained with hematoxylin and eosin or with the periodic acid Schiff reaction (PAS). Additional sections were analyzed by immunohistochemistry.

\section{Immunohistochemical Analyses}

After examination of the hematoxylin and eosin and PAS stains, appropriate sections were selected and processed for immunohistochemistry as described previously (Dombrowski et al, 1997). The antiserum to rat IGF-I was diluted to $1: 250(\mathrm{v} / \mathrm{v})$; antiserum to IGFBP-4 was diluted 1:50 (v/v); and antisera to IGF-IR and M6P/IGF-IIR were diluted 1:100 (v/v). Immunohistochemical analyses using different antisera against IGFBP-1 and IGF-II showed only nonspecific immunoreactivity. Antibodies were detected with the $\mathrm{LSAB}^{+}$ kit (DAKO) and the $\mathrm{DAB}^{+}$kit (DAKO) according to the manufacturer's instructions. Tissue sections were counterstained with hematoxylin, dehydrated, and coverslipped with Eukit (Merck, Darmstadt, Germany) as previously described (Dombrowski et al, 1997).

\section{ISH}

For mRNA ISH analysis, the middle lobe of the liver was removed before perfusion with the fixation cocktail. Slices of liver tissue were frozen in liquid nitrogen and stored at $-80^{\circ} \mathrm{C}$. Prehybridization, hybridization, and washing procedures including the removal of nonspecifically bound probe by RNase A digestion were performed for both antisense and sense strand [ ${ }^{35} \mathrm{~S}$-labeled RNA probes as previously described (Herbst et al, 1991). Sections from preneoplastic hepatic foci and from HCC tissue were processed simultaneously using the same batches of probes and reagents. After exposing the slides for 2 to 6 weeks, autoradiographic detection of bound activity was performed as previously described (Herbst et al, 1991).

\section{Isolation of Total RNA and Northern Blot Analysis}

Total RNA was isolated from rat liver as previously described (Scharf et al, 1995, 1996). For IGFBP-1, total RNA was evaluated using digoxigenin-labeled antisense RNA generated by in vitro transcription with RNA polymerase (Boehringer-Mannheim, Mannheim, Germany) and the $\mathrm{T}_{3}$ promoter of the pBluescript $\mathrm{SK}^{+}$ plasmid as previously described (Scharf et al, 1996). Fragments of the rat IGF-I plasmid (700 bp), the rat 
IGF-II plasmid (500 bp), the rat IGFBP-4 plasmid (444 bp), the rat IGF-IR (265 bp), and the IGF-II/M6PR (500 bp) were $\left[{ }^{32} \mathrm{P}\right]-d C T P$ labeled by random priming. Prehybridization, hybridization, and washing of membranes were performed as previously described (Demori et al, 1997; Scharf et al, 1998b).

\section{Acknowledgements}

The technical assistance of Ms. S. Hupe and Ms. S. Zachmann (Department of Medicine, Gottingen) and Mr. J. Bedorf and Ms. I. Heim (Institute of Pathology, Bonn) is gratefully acknowledged. We thank Mr. R. Schulz and Ms. S. Wolf-Kümmeth (Institute of Pathology, Bonn) for performing the immunohistochemical analyses and Ms. C. Müller (Institute of Pathology, Bonn) for processing the photographic material. We are indebted to Drs. Ling and Shimasaki (Whittier Institute for Diabetes and Endocrinology, La Jolla, California) for providing IGFBP-1 and IGFBP-4 CDNA and antisera to rat IGFBP-1 and IGFBP-4. We are grateful to Drs. LeRoith and Roberts (National Institutes of Health, Bethesda, Maryland) for donating the cDNA for rat IGF-IR and IGF-II/M6PR, to Drs. Schwander and Margot (Department of Internal Medicine, Basel, Switzerland) for providing the rat IGF-1 cDNA, and to Dr. Gammeltoft (Institute of Biochemistry, Copenhagen, Denmark) for the rat IGF-II cDNA. We are indebted to Prof. Pfeifer (Institute of Pathology, Bonn) and Prof. Hartmann (Department of Medicine, Gottingen) for stimulating discussions.

\section{References}

Bach LA and Rechler MM (1995). Insulin-like growth factor binding proteins. Diabet Rev 3:38-61.

Bailyes EM, Navé BT, Soos MA, Orr SR, Hayward AC, and Siddle K (1997). Insulin receptor/IGF-I receptor hybrids are widely distributed in mammalian tissues: Quantification of individual receptor species by selective immunoprecipitation and immunoblotting. Biochem J 327:209-215.

Bannasch P (1996). Pathogenesis of hepatocellular carcinoma: Sequential cellular, molecular, and metabolic changes. Prog Liver Dis 14:161-197.

Baserga R (1999). The IGF-I receptor in cancer research. Exp Cell Res 253:1-6.

Baserga R, Hongo A, Rubini M, Prisco M, and Valentinis B (1997). The IGF-I receptor in cell growth, transformation and apoptosis. Biochim Biophys Acta 1332:F105-126.

Böni-Schnetzler M, Schmid C, Mary J-L, Zimmerli B, Meier PJ, Zapf J, Schwander J and Froesch ER (1990). Insulin regulates the expression of the insulin-like growth factor binding protein 2 mRNA in rat hepatocytes. Mol Endocrinol 4:1320-1326.

Böni-Schnetzler M, Schmid C, Meier PJ, and Froesch ER (1991). Insulin regulates insulin-like growth factor I mRNA in rat hepatocytes. Am J Physiol 260:E846-851.

Braulke T (1999). Type-2 IGF receptor: A multi-ligand binding protein. Horm Metab Res 31:242-246.

Busby WH, Klapper DG, and Clemmons DR (1988). Purification of a 31000-dalton insulin-like growth factor binding protein from human amniotic fluid. J Biol Chem 263:1420314210.

Byrd JC, Devi GR, de Souza AT, Jirtle RL, and MacDonald $R G$ (1999). Disruption of ligand binding to the insulin-like growth factor II/mannose 6-phosphate receptor by cancerassociated missense mutations. J Biol Chem 274:2440824416.

Cariani E, Lasserre C, Seurin D, Hamelin B, Kemeny F, Franco D, Czech MP, Ullrich A, and Brechot C (1988). Differential expression of insulin-like growth factor II mRNA in human primary liver cancers, benign liver tumors, and liver cirrhosis. Cancer Res 48:6844-6849.

Caro JF, Poulos J, Ittoop O, Pories WJ, Flickinger EG, and Shinha MK (1988). Insulin-like growth factor I binding in hepatocytes from human liver, human hepatoma, and normal, regenerating, and fetal liver. J Clin Invest 81:976-981.

Casola S, Ungaro P, Pedone PV, Lazzaro D, Fattori E, Ciliberto G, Zarrilli R, Bruni CB, and Riccio A (1995). Loss of heterozygosity of imprinted genes in SV $40 \mathrm{t} / \mathrm{T}$ antigeninduced hepatocellular carcinomas. Oncogene 11:711-721.

Christofiori G, Naik P, and Hanahan D (1994). A second signal supplied by insulin-like growth factor II in oncogene-induced tumorigenesis. Nature 369:414-418.

Clemmons DR (1997). Insulin-like growth factor binding proteins and their role in controlling IGF actions. Cytokine Growth Factor Rev 8:45-62.

Coppola D, Ferber A, Miura M, Sell C, D’Ambrosio C, Rubin $R$, and Baserga $R$ (1994). A functional insulin-like growth factor I receptor is required for the mitogenic and transforming activities of the epidermal growth factor receptor. Mol Cell Biol 14:4588-4595.

Demori I, Bottazzi C, Voci A, Gallo G, Scharf J-G, and Fugassa E (1997). Tri-iodothyronine increases insulin-like growth factor binding protein-4 expression in rat hepatocytes. J Endocrinol 154:155-165.

De Souza AT, Hankins GR, Washington MK, Orton TC, and Jirtle RL (1995). M6P/IGF2R gene is mutated in human hepatocellular carcinomas with loss of heterozygosity. Nat Genet 11:447-449.

De Souza AT, Yamada T, Mills JJ, and Jirtle RL (1997). Imprinted genes in liver carcinogenesis. FASEB J 11:60-67.

Dombrowski F, Bannasch P, and Pfeifer U (1997). Hepatocellular neoplasms induced by low-number pancreatic islet transplants in streptozotocin diabetic rats. Am J Pathol 150:1071-1087.

Dombrowski F, Filsinger E, Bannasch P, and Pfeifer U (1996). Altered liver acini induced in diabetic rats by portal vein islet isografts resemble preneoplastic hepatic foci in their enzymic pattern. Am J Pathol 148:1249-1256.

Dombrowski F, Klingmüller D, and Pfeifer U (1998). Insulinomas derived from hyperplastic intra-hepatic islet transplants. Am J Pathol 152:1025-1038.

Dombrowski F, Lehringer-Polzin M, and Pfeifer U (1994). Hyperproliferative liver acini after intraportal islet transplantation in streptozotocin-induced diabetic rats. Lab Invest 71:688-699.

Elgin RG, Busby WH, and Clemmons DR (1987). An insulinlike growth factor (IGF) binding protein enhances the biological responses to IGF-I. Proc Natl Acad Sci USA 84:32543258. 
Hartmann H, Schmitz F, Christ B, Jungermann K, and Creutzfeldt W (1990). Metabolic actions of insulin-like growth factor-I in cultured hepatocytes from adult rats. Hepatology 12:1139-1143.

Herbst H, Milani S, Schuppan D, and Stein H (1991). Temporal and spatial patterns of proto-oncogene expression at early stages of toxic liver injury in the rat. Lab Invest 65:324333.

Jirtle RL, Hankins GR, Reisenbichler H, and Boyer IJ (1994). Regulation of mannose 6-phosphate/insulin-like growth factor-II receptors and transforming growth factor beta during liver tumor promotion with phenobarbital. Carcinogenesis 15:1473-1478.

Jones JI and Clemmons DR (1995). Insulin-like growth factors and their binding proteins: Biological actions. Endocr Rev 16:3-34.

Kachra Z, Barash I, Yannopoulos C, Khan MN, Guyda HJ, and Posner BI (1991). The differential regulation by glucagon and growth hormone of insulin-like growth factor (IGF)-I and IGF binding proteins in cultured rat hepatocytes. Endocrinology 128:1723-1730.

Klimek F and Bannasch P (1993). Isoenzyme shift from glucokinase to hexokinase is not an early but a late event in hepatocarcinogenesis. Carcinogenesis 14:1857-1861.

Lammers R, Gray A, Schlessinger J, and Ullrich A (1989). Differential signalling potential of insulin- and IGF-1-receptor cytoplasmic domains. EMBO J 8:1369-1375.

LeRoith D, Baserga R, Helman L, and Roberts CT (1995a). Insulin-like growth factors and cancer. Ann Intern Med 122: 54-59.

LeRoith D, Werner H, Beitner-Johnson D, and Roberts CT (1995b). Molecular and cellular aspects of the insulin-like growth factor I receptor. Endocr Rev 2:143-163.

Macaulay VM (1992). Insulin-like growth factors and cancer. Br J Cancer 65:311-320.

Menuelle P, Binoux M, and Plas C (1995). Regulation by insulin-like growth factor (IGF) binding proteins of IGF-IIstimulated glycogenesis in cultured fetal rat hepatocytes. Endocrinology 136:5305-5310.

Norstedt G, Levinovitz A, Moller C, Eriksson LC, and Andersson $\mathrm{G}$ (1988). Expression of insulin-like growth factor-I (IGF-I) and IGF-II mRNA during hepatic development, proliferation and carcinogenesis in the rat. Carcinogenesis 9:209-213.

Pao Cl, Farmer PK, Begovic S, Villafuerte BC, Wu GJ, Robertson DG, and Phillips LS (1993). Regulation of insulinlike growth factor-I (IGF-I) and IGF-binding protein 1 gene transcription by hormones and provision of amino acids in rat hepatocytes. Mol Endocrinol 7:1561-1568.

Phillips LS, Goldstein S, and Pao Cl (1991). Nutrition and somatomedin. XXVI. Molecular regulation of IGF-I by insulin in cultured rat hepatocytes. Diabetes 40:1525-1530.

Pintar J, Schuller A, Bradshaw S, Cerro J, and Grewal A (1998). Genetic disruption of IGF binding proteins. In: Takano K, Hizuka N, and Takahashi SI, editors. Molecular mechanisms to regulate the activities of insulin-like growth factors. Amsterdam: Elsevier Science, 65-70.

Prisco M, Romano G, Peruzzi F, Valentinis B, and Baserga $R$ (1999). Insulin and IGF-I receptors signaling in protection from apoptosis. Horm Metab Res 31:80-89.
Rogler CE, Rogler LE, Yang D, Breiteneder-Geleef S, Gong S, and Wang $\mathrm{H}$ (1995). Contributions of hepadnavirus research to our understanding of hepatocarcinogenesis. In: Jirtle RL, editor. Liver regeneration and carcinogenesis: Molecular and cellular mechanisms. San Diego: Academic Press, 113-140.

Rumsby PC, Davies MJ, Price RJ, and Lake BG (1994). Effect of some peroxisome proliferators on transforming growth factor-beta 1 gene expression and insulin-like growth factor II/mannose-6-phosphate receptor gene expression in rat liver. Carcinogenesis 15:419-421.

Scharf J-G, Knittel T, Dombrowski F, Müller L, Saile B, Braulke T, Hartmann H, and Ramadori G (1998a). Characterization of the IGF axis components in isolated rat hepatic stellate cells. Hepatology 27:1275-1284.

Scharf J-G, Ramadori G, Braulke T, and Hartmann H (1995). Cellular localization and hormonal regulation of biosynthesis of insulin-like growth factor binding proteins and of the acid-labile subunit within rat liver. Prog Growth Factor Res 6:175-180.

Scharf J-G, Ramadori R, Braulke T, and Hartmann H (1996). Synthesis of insulinlike growth factor binding proteins and of the acid-labile subunit in primary cultures of rat hepatocytes, of Kupffer cells, and in cocultures: Regulation by insulin, insulinlike growth factor, and growth hormone. Hepatology 23:818-827.

Scharf J-G, Schmidt-Sandte W, Pahernik SA, Ramadori G, Braulke T, and Hartmann H (1998b). Characterization of the insulin-like growth factor axis in a human hepatoma cell line (PLC). Carcinogenesis 19:2121-2128.

Schirmacher P, Held WA, Yang D, Chisari FV, Rustum Y, and Rogler CE (1992). Reactivation of insulin-like growth factor II during hepatocarcinogenesis in transgenic mice suggests a role in malignant growth. Cancer Res 52:2549-2556.

Schmitz F, Bresciani R, Hartmann H, and Braulke T (1995). Effect of insulin-like growth factor II on uptake of arylsulfatase $\mathrm{A}$ by cultured rat hepatocytes and Kupffer cells. J Hepatol 22:356-363.

Scott CD, Martin JL, and Baxter RC (1985a). Rat hepatocyte insulin-like growth factor I and binding protein: Effect of growth hormone in vitro and in vivo. Endocrinology 116: 1102-1107.

Scott CD, Martin JL, and Baxter RC (1985b). Production of insulin-like growth factor I and its binding protein by adult rat hepatocytes in primary culture. Endocrinology 116:10941101.

Shimasaki S and Ling N (1991). Identification and molecular characterization of insulin-like growth factor binding proteins (IGFBP-1, -2, -3, IGFBP-4, -5 and -6). Prog Growth Factor Res 3:243-266.

Stylianopoulou F, Herbert J, Soares MB, and Efstratiadis A (1988). Expression of the insulin-like growth factor II gene in the choroid plexus and the leptomeninges of the adult rat central nervous system. Proc Natl Acad Sci USA 85:141-145.

Sue SR, Chari RS, Kong FM, Mills JJ, Fine RL, Jirtle RL, and Meyers WC (1995). Transforming growth factor-beta receptors and mannose 6-phosphate/insulin-like growth factor-II receptor expression in human hepatocellular carcinoma. Ann Surg 222:171-178. 
Villafuerte BC, Goldstein S, Murphy LJ, and Phillips LS (1991). Nutrition and somatomedin. XXV. Regulation of insulin-like growth factor binding protein-1 in primary cultures of normal rat hepatocytes. Diabetes 40:837-841.

Villafuerte BC, Goldstein S, Robertson DG, Pao Cl, Murphy LJ, and Phillips LS (1992). Nutrition and somatomedin XXIX. Molecular regulation of IGFBP-1 in hepatocyte primary culture. Diabetes 41:835-842.

Villafuerte BC, Koop BL, Pao Cl, Luming G, Birdsong GG, and Phillips LS (1994). Coculture of primary rat hepatocytes and nonparenchymal cells permits expression of insulin-like growth factor binding protein-3 in vitro. Endocrinology 134: 2044-2050.

Villafuerte BC, Koop BL, Pao Cl, and Phillips LS (1995). Glucocorticoid regulation of insulin-like growth factorbinding protein-3. Endocrinology 136:1928-1933.

von Figura K, Gieselmann V, and Hasilik A (1984). Antibody to mannose 6-phosphate specific receptor induces receptor deficiency in human fibroblasts. EMBO J 3:1281-1286.

Wada I, Kanada H, Nomura K, Kato Y, Machinami R, and Kitagawa T (1999). Failure to detect genetic alteration of the mannose-6-phosphate/insulin-like growth factor 2 receptor (M6P/IGF2R) gene in hepatocellular carcinomas in Japan. Hepatology 29:1718-1721.
Wells A (1999). EGF receptor. Int J Biochem Cell Biol 31:637643.

Werner H, Woloschak M, Adamo M, Shen-Orr Z, Roberts CT Jr, and LeRoith D (1989). Developmental regulation of the rat insulin-like growth factor I receptor gene. Proc Natl Acad Sci USA 86:7451-7455.

Yang D, Alt E, and Rogler CE (1993). Coordinate expression of N-myc 2 and insulin-like growth factor II in precancerous altered hepatic foci in woodchuck hepatitis virus carriers. Cancer Res 53:2020-2027.

Yang D and Rogler CE (1991). Analysis of insulin-like growth factor II (IGF-II) expression in neoplastic nodules and hepatocellular carcinomas of woodchucks utilizing in situ hybridization and immunocytochemistry. Carcinogenesis 12:18931901. 